\title{
Chemical Preparation of Pure and Strontium- and/or Magnesium-Doped Lanthanum Gallate Powders
}

\author{
A. Cüneyt Taş, ${ }^{*}$ Peter J. Majewski, and Fritz Aldinger* \\ Max-Planck-Institut für Metallforschung, Pulvermetallurgisches Laboratorium, Stuttgart D-70569, Germany
}

\begin{abstract}
Powder compositions of $\mathrm{LaGaO}_{3}, \mathrm{La}_{0.9} \mathrm{Sr}_{0.1} \mathrm{GaO}_{2.95}$, and $\mathrm{La}_{0.8} \mathrm{Sr}_{0.2} \mathrm{Ga}_{0.83} \mathrm{Mg}_{0.17} \mathrm{O}_{2.815}$ were prepared via a Pechini-type process that uses citric acid and ethylene glycol. The calcination behavior of the precursor powders of the abovementioned phases was studied in the temperature range of $200^{\circ}-1400^{\circ} \mathrm{C}$ in an air atmosphere. Characterization of the powder samples were performed using several processes, including X-ray diffractometry, thermogravimetry/differential thermal analysis, Fourier transform infrared spectroscopy, scanning electron microscopy, inductively coupled plasmaatomic emission spectroscopy, and carbon and nitrogen analyses.
\end{abstract}

\section{Introduction}

$\mathrm{L}$ ANTHANUM GALLATE $\left(\mathrm{LaGaO}_{3}\right)$ ceramics that have been doped

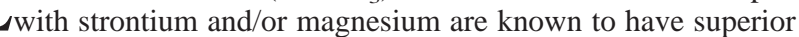
oxygen-ion-conducting properties, ${ }^{1,2}$ in comparison, for instance, to yttria-stabilized zirconia electrolytes. Several researchers recently synthesized strontium- and magnesium-doped $\mathrm{LaGaO}_{3}$ ceramics, using the conventional "solid-state reactive firing" method. ${ }^{1-4}$ The promising electrode performance of these ceramics, ${ }^{5}$ and their mechanical properties, ${ }^{6-8}$ already have been reported. Stevenson et al. ${ }^{9}$ first used the technique of combustion synthesis ${ }^{10-15}$ to successfully prepare strontium- and magnesiumdoped $\mathrm{LaGaO}_{3}$ powders. More recently, the combustion synthesis of strontium- and magnesium-doped $\mathrm{LaGaO}_{3}$ ceramics has been reported for the manufacture of thin films of the same. ${ }^{16}$ In contrast, a coprecipitation route (with $\mathrm{NH}_{4} \mathrm{OH}$ addition) from an aqueous mixture of the acetates of lanthanum, strontium, and magnesium, as well as that of gallium nitrate, also has been attempted by Huang et al. ${ }^{17}$ In a separate study, those research$\operatorname{ers}^{18}$ also briefly mentioned the use of the Pechini method to synthesize strontium- and magnesium-doped $\mathrm{LaGaO}_{3}$ ceramic powders.

Pechini $^{19}$ first invented this process, which is a versatile powder-synthesis process that involves the formation of a polymeric resin, using citric acid and ethylene glycol. This process later was used extensively to manufacture ceramic oxide powders for solid oxide fuel cells (SOFCs). ${ }^{20-24}$

In this powder-synthesis route, citric acid forms poly(basic acid) chelates with the metal cations. These chelates undergo polyesterification, when heated with a poly(hydroxy alcohol), such as ethylene glycol, at a temperature of $\sim 150^{\circ} \mathrm{C}$ to form a polymeric precursor resin. ${ }^{20,21}$ The cations are expected to be dispersed uniformly throughout the polymeric resin. Additional heating of the resin in air (at $>400^{\circ} \mathrm{C}$ ) results in the removal of organics and the formation of a char with a controlled cation stoichiometry, with

E. D. Wachsman-contributing editor

Manuscript No. 188728. Received February 22, 2000; approved June 1, 2000

${ }^{\star}$ Member, American Ceramic Society. little cation segregation. Then, the char is heated to higher temperatures and oxidized to form the oxide ceramics. We have used this Pechini-type chemical-preparation route to synthesize pure and strontium- and/or magnesium-doped $\mathrm{LaGaO}_{3}$ ceramics. The product powders are fully characterized (as identified via, for example, phase distribution, particle size and morphology, infrared (IR) behavior, and thermogravimetric and chemical analyses).

\section{Powder Synthesis and Characterization}

The powders were synthesized using $0.15 M-0.3 M$ stock solutions of each of the following chemicals: $\mathrm{La}\left(\mathrm{NO}_{3}\right)_{3} \cdot 9 \mathrm{H}_{2} \mathrm{O}(99 \%$ pure, Merck, Darmstadt, Germany), $\mathrm{Ga}\left(\mathrm{NO}_{3}\right)_{3} \cdot x \mathrm{H}_{2} \mathrm{O}(99.999 \%$ pure, Lot No. 12806ER, Sigma-Aldrich Chemie GmbH, Steinheim, Germany), $\mathrm{Sr}\left(\mathrm{NO}_{3}\right)_{2} \quad(99 \%$ pure, Merck), and $\mathrm{Mg}\left(\mathrm{NO}_{3}\right)_{2} \cdot 6 \mathrm{H}_{2} \mathrm{O}$ (99\% pure, Merck). The stock solutions were prepared by dissolving appropriate amounts of the starting chemicals in deionized water. The value of $x$ given in the above-given formula of gallium nitrate (as assigned by the manufacturer) was determined experimentally to be 4.06 (using inductively coupled plasma-atomic emission spectroscopy (ICP-AES) analyses that we performed on the stock solutions).

A Pechini-type process ${ }^{19,25}$ was used to prepare the polymeric precursors. For each precursor, exactly stoichiometric amounts of nitrate stock solutions that corresponded to a 5-g yield of lanthanum gallate resins (pure or doped with strontium and/or magnesium) were mixed initially in a glass beaker (capacity of $50 \mathrm{~mL}$ ) to obtain a total solution volume of $\sim 25 \mathrm{~mL}$. Then, a mixture of 60 wt $\%$ citric acid monohydrate $\left(\mathrm{C}_{6} \mathrm{H}_{8} \mathrm{O}_{7}, 99.9 \%\right.$ pure, Merck) and 40 wt $\%$ ethylene glycol $\left(\mathrm{C}_{2} \mathrm{H}_{6} \mathrm{O}_{2}, 99 \%\right.$ pure, Merck) (the molar ratio of citric acid to total cations was maintained constant at 1.88) was added to this cation solution. This solution was homogenized by stirring at room temperature for $1 \mathrm{~h}$. Then, the resulting clear solution was evaporated (in a period of $3 \mathrm{~h}$ ) on a hot plate until first a clear yellow gel and then a dark brown resin formed. The obtained resins (following overnight drying in an oven at $100^{\circ} \mathrm{C}$ ) were scraped off the beakers with a spatula, then ground by hand using an agate mortar and pestle, and finally calcined isothermally in a stagnant-air-atmosphere box furnace over a temperature range of $200^{\circ}-1400^{\circ} \mathrm{C}$. Each calcination batch of powders was heated to the specified temperature at a rate of $5^{\circ} \mathrm{C} / \mathrm{min}$, annealed at this temperature for $6 \mathrm{~h}$, and then furnace-cooled to room temperature.

The phase constitution of the powders was analyzed, as a function of temperature (on isothermally calcined samples), using a powder X-ray diffractometer (Model D-5000, Siemens GmbH, Karlsruhe, Germany) with monochromated $\mathrm{CuK \alpha}{ }_{1}$ radiation (40 $\mathrm{kV}, 30 \mathrm{~mA}$ ). For determination of the lattice parameters, a scan rate of $0.2^{\circ} 2 \theta / \mathrm{min}$ (over the range of $10^{\circ}-80^{\circ} 2 \theta$ ) was used; a silicon external standard, along with the Appleman Least Squares Refinement Program, ${ }^{26}$ was used to correct for systematic errors.

The pyrolysis of accurately weighed 150-mg portions of ground, amorphous resin samples were monitored via simultaneous thermogravimetric and differential thermal analysis (TG/ DTA) (Model STA501, Bähr GmbH, Bremen, Germany) in an air atmosphere at a heating rate of $5^{\circ} \mathrm{C} / \mathrm{min}$. $\mathrm{Al}_{2} \mathrm{O}_{3}$ was used as the reference material in all the TG/DTA runs. Fourier transform 
infrared (FTIR) spectroscopy analyses of the samples were performed (Model IFS 66, Bruker GmbH, Karlsruhe, Germany) after they were mixed $(1 \mathrm{wt} \%)$ with dry $\mathrm{KBr}$ to form the pellets that are used in these analyses. Brunauer-Emmitt-Teller (BET) surface area measurements (Model Gemini 2370, Micromeritics, Norcross, GA) of the precursors also were performed to obtain the surface area as a function of the calcination temperature. The bulk densities of some of the green and sintered samples were measured via the Archimedes method, following ASTM Standard C372$73 .^{27}$

The residual carbon and nitrogen contents of the uncalcined and calcined powders were determined using a combustion-IR absorption method (Model CS-800, Eltra GmbH, Neuss, Germany). ICP-AES analyses were performed to obtain quantitative elemental information (Model JY-70Plus, Jobin Yvon S.A., Longjumeau, France) about the samples. The powder morphologies were monitored using scanning electron microscopy (SEM) (Model DSM 982-Gemini, Zeiss GmbH, Oberkochen, Germany).

\section{Results and Discussion}

The phase-evolution behaviors of pure (i.e., $\mathrm{LaGaO}_{3}$, denoted as LG) and doped lanthanum gallate samples (i.e., $\mathrm{La}_{0.9} \mathrm{Sr}_{0.1} \mathrm{GaO}_{2.95}$ (denoted as LSG) and $\mathrm{La}_{0.8} \mathrm{Sr}_{0.2} \mathrm{Ga}_{0.83} \mathrm{Mg}_{0.17} \mathrm{O}_{2.815}$ (denoted as LSGM)) are exhibited by the XRD spectra given in Figs. 1-3. Undoped lanthanum gallate (LG) precursors were X-ray amorphous, even after $6 \mathrm{~h}$ of calcination at $500^{\circ} \mathrm{C}$; these amorphous powders first started to crystallize into a phase mixture of $\mathrm{Ga}_{2} \mathrm{O}_{3}$ (ICDD ${ }^{\dagger}$ Powder Diffraction File Card No. 6-0503), $\mathrm{La}_{2} \mathrm{O}_{3}$ (ICDD Powder Diffraction File Card No. 5-0602), and $\mathrm{LaGaO}_{3}$ (ICDD Powder Diffraction File Card No. 83-0566, orthorhombic) over a temperature range of $500^{\circ}-700^{\circ} \mathrm{C}$. Samples that were heated at $\geq 850^{\circ} \mathrm{C}$ for $6 \mathrm{~h}$ only showed the presence of the LG phase. After calcination in air at $1200^{\circ} \mathrm{C}$ for $6 \mathrm{~h}$ (see Fig. 1, the top XRD trace), LG samples were single phase and orthorhombic (space group Pbnm), with experimental lattice parameters of $a=5.489 \AA, b=$ $5.519 \AA$, and $c=7.751 \AA$, which are in close agreement with the previously reported values. ${ }^{3}$

LSG samples (after calcination at $1340^{\circ} \mathrm{C}$ for $6 \mathrm{~h}$ ) also had an orthorhombic crystal structure, with experimental lattice parameters of $a=5.491 \AA, b=5.523 \AA$, and $c=7.764 \AA$. Although single-phase LG could be formed from the starting X-rayamorphous resins at temperatures as low as $850^{\circ} \mathrm{C}$, single-phase

${ }^{\dagger}$ International Centre for Diffraction Data, Newtown Square, PA (formerly Joint Committee for Powder Diffraction Standards (JCPDS), Swarthmore, PA).
LSG could be produced only after calcination at $1340^{\circ} \mathrm{C}$ for $6 \mathrm{~h}$ (see Fig. 2). The resins with an LSG stoichiometry, after calcination at $1200^{\circ} \mathrm{C}$, still contained the secondary phases of $\mathrm{LaSrGaO}_{4}$ (ICDD Powder Diffraction File Card Nos. 24-1208 and 80-1806) and $\mathrm{LaSrGa}_{3} \mathrm{O}_{7}$ (ICDD Powder Diffraction File Card No. 450637).

LSGM resins that had been calcined for $6 \mathrm{~h}$ at $500^{\circ} \mathrm{C}$ were X-ray amorphous. After calcination at $700^{\circ} \mathrm{C}$ for $6 \mathrm{~h}, \mathrm{LaOOH}$ (ICDD Powder Diffraction File Card No. 19-0656) and $\mathrm{LaSrGa}_{3} \mathrm{O}_{7}$ (ICDD Powder Diffraction File Card No. 45-0637) were the first two phases to crystallize. First, an LSGM perovskite phase crystallized after calcination at $850^{\circ} \mathrm{C}$ for $6 \mathrm{~h}$. Precursor powders consisted of a mixture of four or five phases over the calcination temperatures of $850^{\circ}$ and $1000^{\circ} \mathrm{C}$. The phases observed in these samples were indicated in the caption for Fig. 3. On the other hand, the resins of the LSGM stoichiometry, even after calcination at $1400^{\circ} \mathrm{C}$ for $6 \mathrm{~h}$ (Fig. 3), still were not single-phase and contained $\sim 4-5 \mathrm{wt} \%$ of a mixture of the undesired $\mathrm{LaSrGaO}_{4}$ and $\mathrm{LaSrGa}_{3} \mathrm{O}_{7}$ phases, as also previously reported ${ }^{4,5}$ for the conventionally synthesized (i.e., the mixed-oxide route) LSGM powders.

However, the crystal structures of the LSGM phase present in the biphasic samples (after calcination at $1400^{\circ} \mathrm{C}$ ) of this study were noncubic (i.e., pseudo-orthorhombic). The profound peak splitting that was detected-especially in the peaks that were located at $57.7^{\circ}$, $67.7^{\circ}$, and $77.1^{\circ} 20$-proved the noncubic structure. This finding about the crystal structure of LSGM is consistent with the recent powder neutron-diffraction study by Ishihara et al. ${ }^{28}$ for the specific stoichiometry of $\mathrm{La}_{0.9} \mathrm{Sr}_{0.1} \mathrm{Ga}_{0.8} \mathrm{Mg}_{0.2} \mathrm{O}_{2.85}$ but is in sharp contrast to several other reports. ${ }^{2-5,16-18}$

Ongoing work (using the mixed-oxide or combustion-synthesis routes) in our group ${ }^{29}$ on the phase equilibria and phase-stability studies in the $\mathrm{La}_{2} \mathrm{O}_{3}-\mathrm{SrO}-\mathrm{Ga}_{2} \mathrm{O}_{3}, \mathrm{La}_{2} \mathrm{O}_{3}-\mathrm{MgO}-\mathrm{Ga}_{2} \mathrm{O}_{3}$, and $\mathrm{La}_{2} \mathrm{O}_{3}-\mathrm{SrO}-\mathrm{MgO}-\mathrm{Ga}_{2} \mathrm{O}_{3}$ systems at $1400^{\circ} \mathrm{C}$ in air already indicates that the solubility of strontium and magnesium in LSGM ceramics seems to decrease as the temperature decreases (i.e., to $<1400^{\circ} \mathrm{C}$ ), which results in the formation of the 113 phase (i.e., $\mathrm{LaSrGa}_{3} \mathrm{O}_{7}$ ), regardless of the ceramic synthesis technique that is used. Therefore, exact determination of the compositional boundaries of the homogeneity region of LSGM within the quaternary $\mathrm{La}_{2} \mathrm{O}_{3}-\mathrm{SrO}-\mathrm{MgO}-\mathrm{Ga}_{2} \mathrm{O}_{3}$ system is crucial before any assessment of the secondary phases that are observed during the processing of these ceramics.

The presence of secondary phases, in differing amounts after the high-temperature heatings of our loose (i.e., noncompacted) Pechinitype powders, is mainly due to the short calcination times (i.e., $6 \mathrm{~h}$ ) at the stated temperatures. Stevenson et al. ${ }^{9}$ previously reported that, for

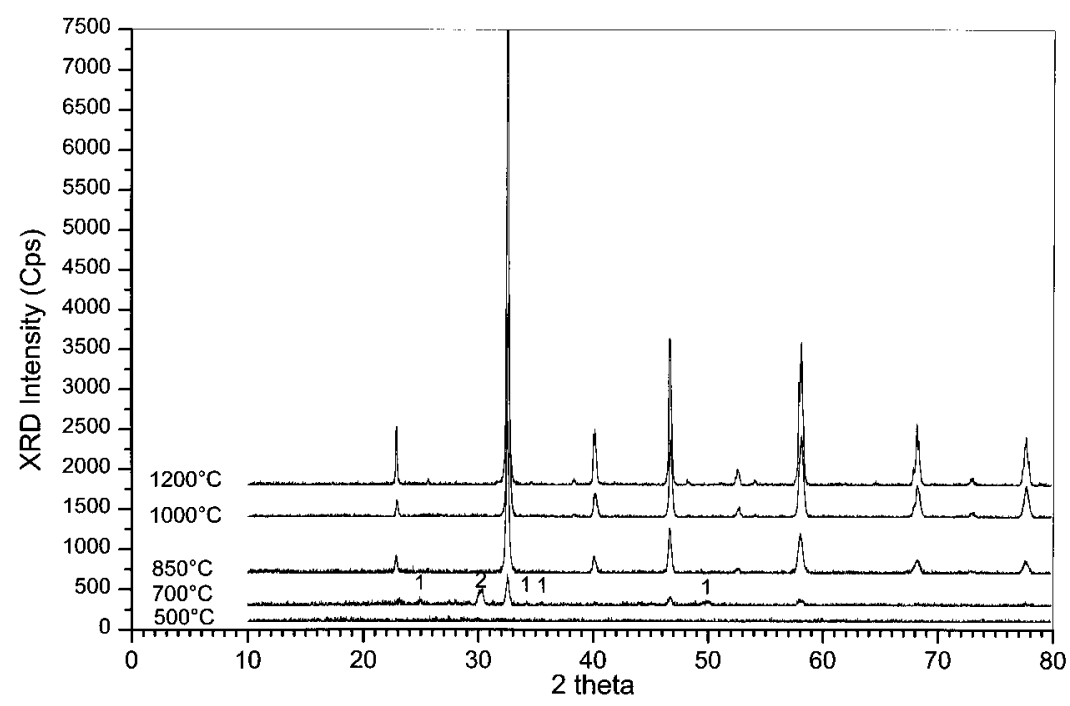

Fig. 1. XRD spectra of $\mathrm{LaGaO}_{3}$ precursor powders calcined at different temperatures. Secondary phases observed are indicated (" 1 ," Ga $\mathrm{O}_{3}$ peak and "2," $\mathrm{La}_{2} \mathrm{O}_{3}$ peak). 


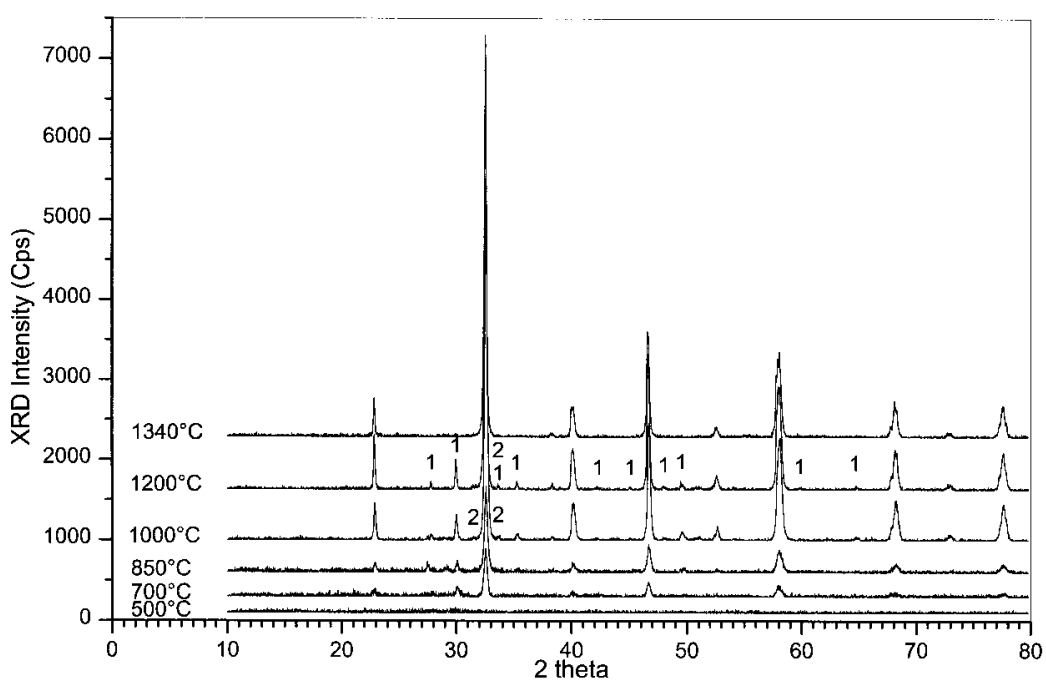

Fig. 2. XRD spectra of $\mathrm{La}_{0.9} \mathrm{Sr}_{0.1} \mathrm{GaO}_{2.95}$ precursor powders calcined at different temperatures. Secondary phases observed are indicated (" 1 ," $\mathrm{LaSrGa} \mathrm{O}_{7}$ peak and "2," $\mathrm{LaSrGaO}_{4}$ peak).

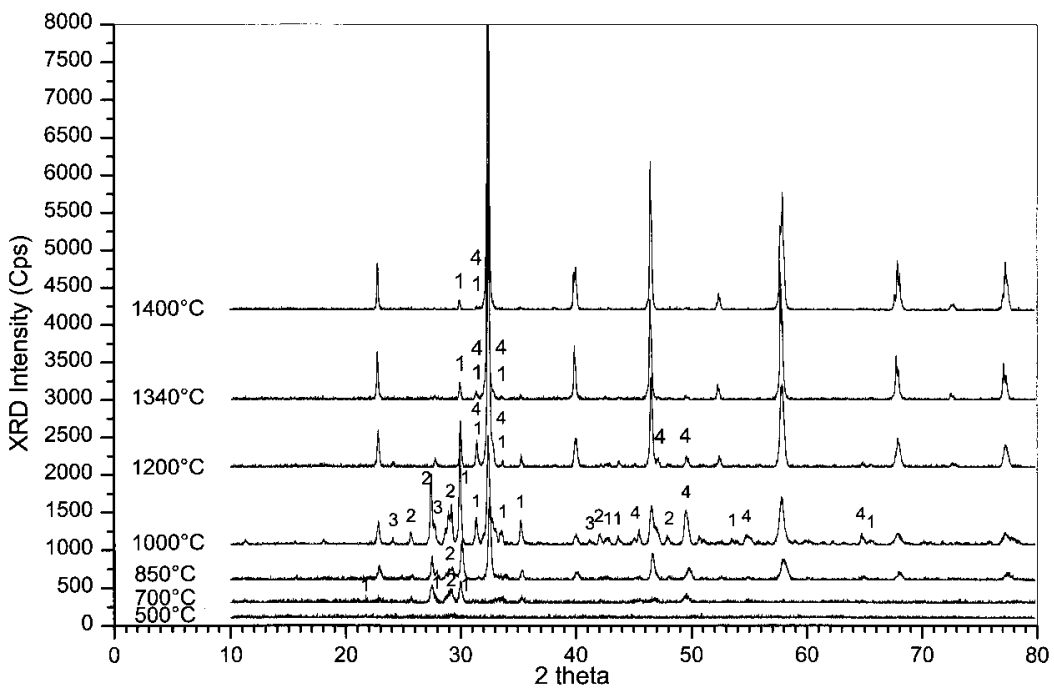

Fig. 3. XRD spectra of $\mathrm{La}_{0.8} \mathrm{Sr}_{0.2} \mathrm{Ga}_{0.83} \mathrm{Mg}_{0.17} \mathrm{O}_{2.815}$ precursor powders calcined at different temperatures. Secondary phases observed are indicated ("1," $\mathrm{LaSrGa}_{3} \mathrm{O}_{7}$ peak, "2," $\mathrm{LaOOH}$ peak, "3," $\mathrm{La}_{2} \mathrm{O}_{3}$ peak, and "4," $\mathrm{LaSrGaO}_{4}$ peak).

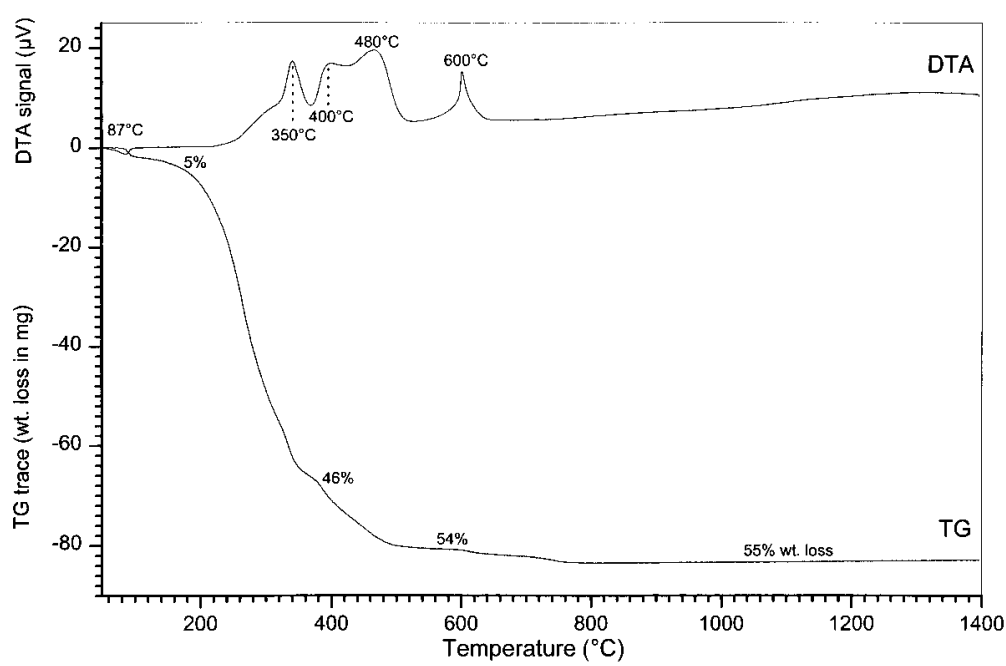

Fig. 4. TG/DTA spectra of LSGM precursors. 
Table I. Results of Residual Carbon Analyses

\begin{tabular}{cccc}
\hline \multirow{2}{*}{$\begin{array}{c}\text { Temperature } \\
\left({ }^{\circ} \mathrm{C}\right)\end{array}$} & \multicolumn{3}{c}{ Carbon content (wt\%) } \\
\cline { 2 - 4 } & $\mathrm{LaGaO}_{3}$ & $\mathrm{La}_{0.9} \mathrm{Sr}_{0.1} \mathrm{GaO}_{2.95}$ & $\mathrm{La}_{0.8} \mathrm{Sr}_{0.2} \mathrm{Ga}_{0.83} \mathrm{Mg}_{0.17} \mathrm{O}_{2.815}$ \\
\hline 100 & $31.7(3)$ & $33.3(2)$ & $32.7(6)$ \\
350 & $10.3(3)$ & $10.4(1)$ & $13.8(2)$ \\
500 & $0.921(2)$ & $0.899(4)$ & $0.937(3)$ \\
700 & $0.530(3)$ & $0.550(5)$ & $0.480(4)$ \\
850 & $0.059(1)$ & $0.143(9)$ & $0.168(3)$ \\
1000 & $0.042(2)$ & $0.050(3)$ & $0.060(2)$ \\
1340 & 0.010 & $0.0124(2)$ & $0.0143(4)$ \\
\hline
\end{tabular}

the combustion-synthesized $\mathrm{La}_{0.9} \mathrm{Sr}_{0.1} \mathrm{Ga}_{0.8} \mathrm{Mg}_{0.2} \mathrm{O}_{3-\delta} \quad$ samples (which were later calcined at $650^{\circ} \mathrm{C}$, followed by isostatic pressing into pellets), heating the pellets at $1400^{\circ} \mathrm{C}$ for $2 \mathrm{~h}$ was not sufficient to produce single-phase LSGM ceramics. The current work in our group, ${ }^{29}$ on either the combustion-synthesized or mixed-oxide route (with intermediate regrinding, repelletizing and reheating steps) samples, showed that increasing the calcination time (at $1400^{\circ} \mathrm{C}$ ) of LSGM ceramics (in samples that have the same stoichiometry of this study) from $6 \mathrm{~h}$ to $24 \mathrm{~h}$, together with the cold isostatic pressing (CIPing) of the powders into a pellet, or increasing the firing temperature from $1400^{\circ} \mathrm{C}$ to $1470^{\circ}-1500^{\circ} \mathrm{C}$, removed the secondary phases.

The basic issue in the processing of LSGM ceramics, in our opinion, actually is not the formation of single-phase perovskites, e.g., at $1470^{\circ}$ or $1500^{\circ} \mathrm{C},,^{4,16}$ but is rather the point of further studies that are still necessary to develop alternative routes that might provide a decrease in the processing temperature. It is known that even the single-phase LSGM ceramics that are initially produced at temperatures of $\geq 1400^{\circ} \mathrm{C}$ may not be thermally stable over prolonged times at the typical operating temperatures of SOFCs $\left(700^{\circ}-800^{\circ} \mathrm{C}\right.$ ), and the secondary phases (such as $\mathrm{LaSrGa}_{3} \mathrm{O}_{7}$ and $\mathrm{LaSrGaO}_{4}$ ) may reappear in these ceramics. ${ }^{29}$

In a relatively recent publication, Huang et al. ${ }^{18}$ briefly mentioned the possibility of the synthesis of LSGM ceramics via the Pechini method as an alternative route to their ammonia-induced coprecipitation method. They have reported the use of an almostequimolar mixture of citric acid and ethylene glycol to form the polymeric resins from the nitrate solution. However, those authors $^{18}$ did not provide any XRD, TG/DTA, FTIR, and SEM data or discussion in the above-mentioned publication for the LSGM samples that have been produced using the Pechini method; unfortunately, for this reason, we now do not have the chance to compare the results of the present study with their findings.

The results of thermal analysis (TG/DTA) on the LSGM ceramics of this study are given in Fig. 4. The DTA traces of
LSGM resins showed exotherms at $\sim 350^{\circ}-400^{\circ} \mathrm{C}, 480^{\circ} \mathrm{C}$, and $600^{\circ} \mathrm{C}$. The first two exotherms were associated with charring of the polymer, the third exotherm $\left(480^{\circ} \mathrm{C}\right)$ was associated with the pyrolysis of the organics, and the last exotherm $\left(600^{\circ} \mathrm{C}\right)$ resulted from char burnout. TG analysis showed that most of the weight

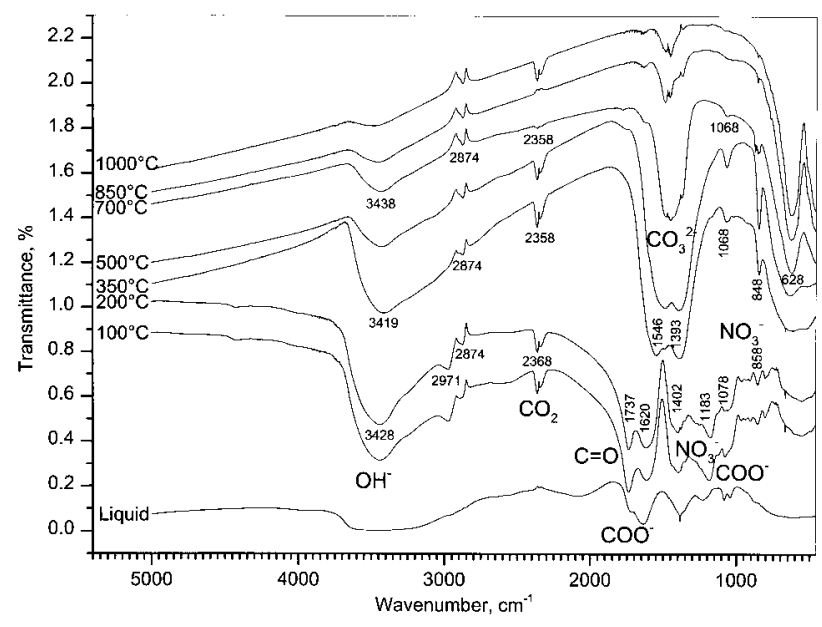

Fig. 6. FTIR spectra of LSG precursors, as a function of temperature.

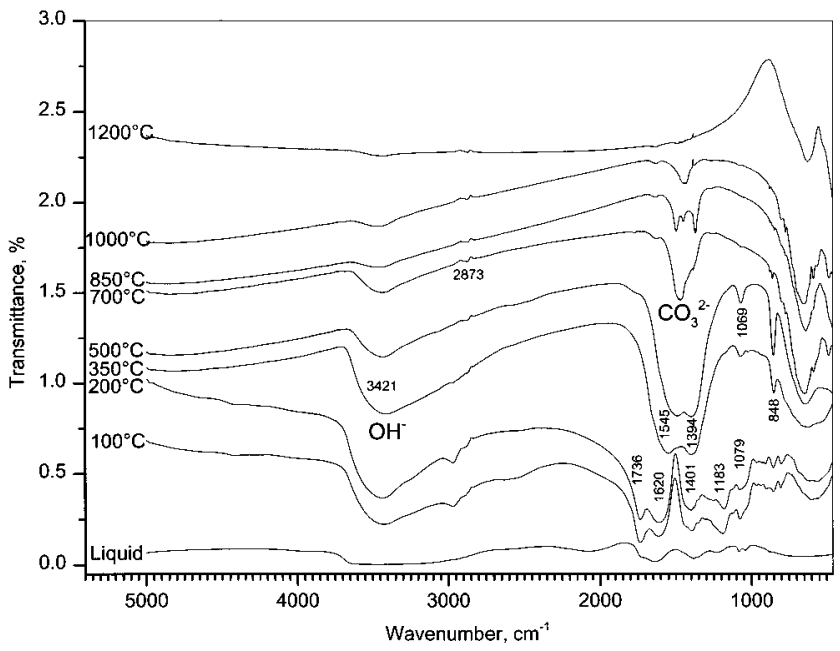

Fig. 7. FTIR spectra of LSGM precursors, as a function of temperature.

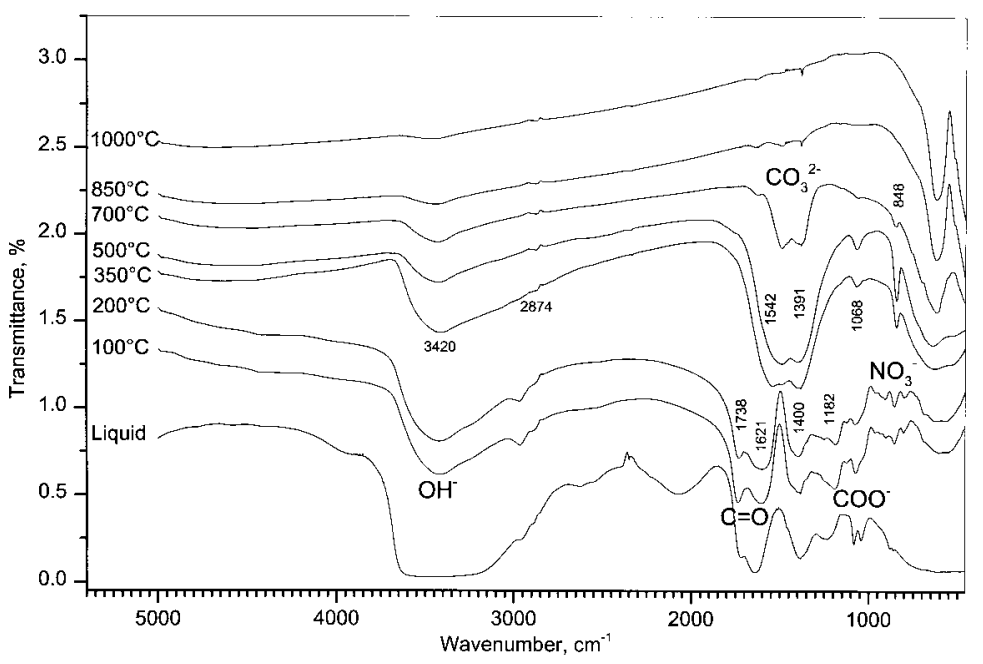

Fig. 5. FTIR spectra of LG precursors, as a function of temperature. 

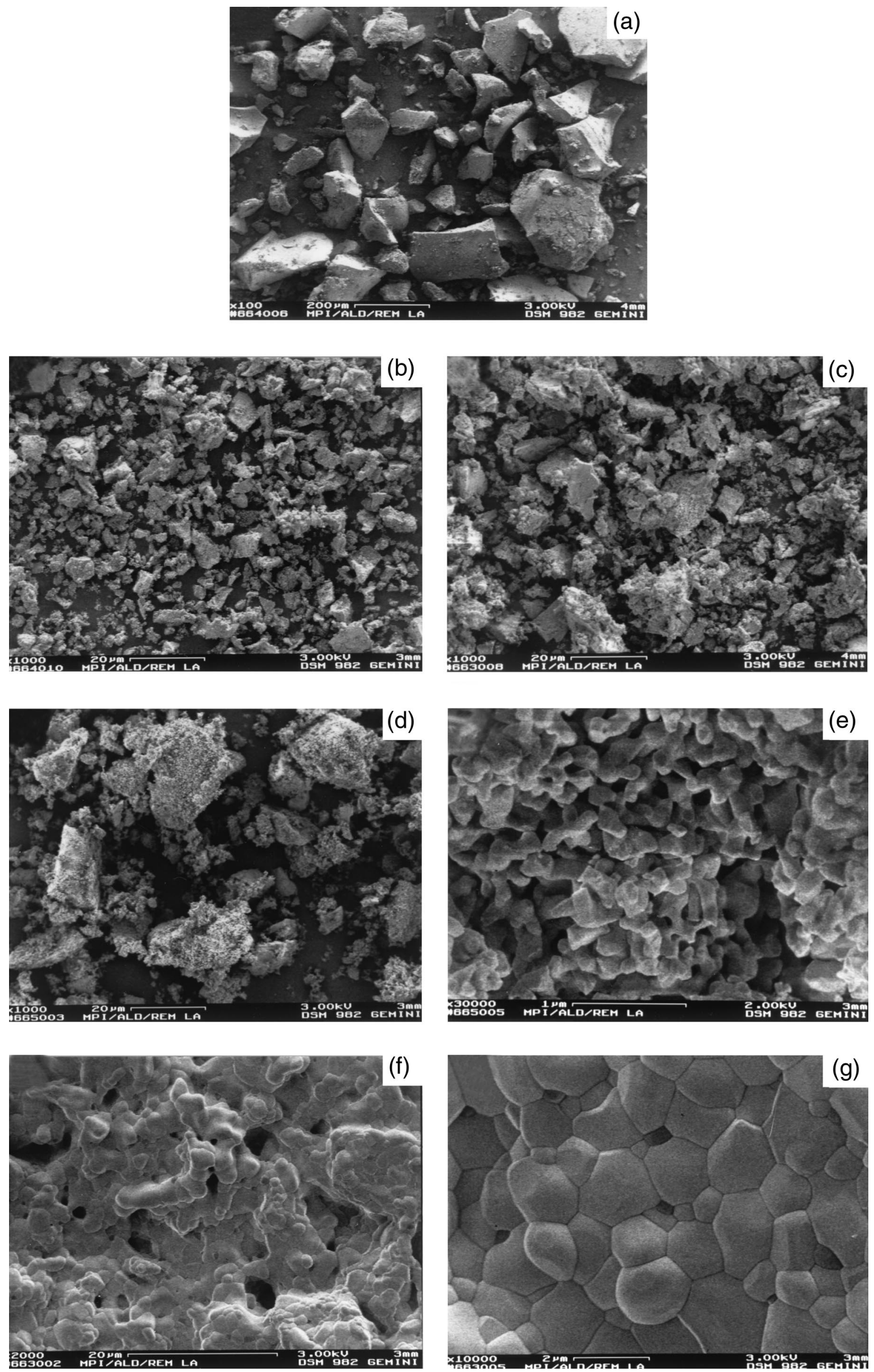

Fig. 8. SEM micrographs of LSGM precursors after heating at (a) $100^{\circ}$, (b) $500^{\circ}$, (c) $700^{\circ}$, and (d) and (e) $1000^{\circ} \mathrm{C}$. Figures 8 (f) and (g) show the pellet fracture surface after heating at $1400^{\circ} \mathrm{C}$ for $8 \mathrm{~h}$. 
loss occurred at $200^{\circ}-500^{\circ} \mathrm{C}$. This temperature range corresponded exactly with the range where polymer burnout occurred.

The results of residual carbon analyses (as a function of calcination temperature) are shown in Table I. The nitrogen content of the $100^{\circ} \mathrm{C}$-calcined precursor samples were in the range of 1.05-1.2 wt\%; however, as the calcination temperatures increased (starting from $200^{\circ} \mathrm{C}$ ), the nitrogen content decreased to levels below the reliable detection level (i.e., $100 \mathrm{ppm}$ ) of the equipment that was used.

ICP-AES analysis results (in terms of molar ratios) of the $1340^{\circ} \mathrm{C}$-calcined samples of LSG compositions (i.e., $\mathrm{La} / \mathrm{Sr}=$ 8.984 and $\mathrm{La} / \mathrm{Ga}=0.912)$ and $\mathrm{LSGM}(\mathrm{La} / \mathrm{Sr}=3.990, \mathrm{La} / \mathrm{Ga}=$ 0.958 , and $\mathrm{La} / \mathrm{Mg}=4.693$ ) only approximated the theoretical molar ratios of elements that were expected to be present. The above-given figures represent the averages of three separate ICP runs on reproduced samples. However, the $\mathrm{La} / \mathrm{Ga}$ atomic ratio in the LSGM samples represents a $0.6 \%$ deviation from the nominal formula, whereas the deviation in the same ratio for the LSG samples increased to $\sim 1.3 \%$. These fluctuations can be ascribed to a certain degree of practical inefficiency in scraping the formed resins from the bottom and walls of the glass reaction beakers. FTIR spectroscopy plots of the LG, LSG, and LSGM samples (as a function of calcination temperature) are given in Figs. 5-7, respectively. The broad band located at $3500-2500 \mathrm{~cm}^{-1}$ is due to $\mathrm{O}-\mathrm{H}$ stretching. The presence of the citrate ion was detected by the band located at $2990-2874 \mathrm{~cm}^{-1}$ at low calcination temperatures. Dissolved or atmospheric $\mathrm{CO}_{2}$ was indicated by the band located at $2350 \mathrm{~cm}^{-1}$. The carboxylate anion $\left(\mathrm{COO}^{-}\right)$stretching was indicated by two bands in the range of $1740-1380 \mathrm{~cm}^{-1}$, and the structural $\mathrm{CO}_{3}^{2-}$ was observed by the broad band at $1500-1300$ $\mathrm{cm}^{-1}$, as well as at $1080-1030 \mathrm{~cm}^{-1}$ and $800 \mathrm{~cm}^{-1}$. The existence of a covalent carbonyl bond $(\mathrm{C}=\mathrm{O}$ stretching vibration) was indicated by the bands located at $1730-1700$ and $1190-1075$ $\mathrm{cm}^{-1}$, and the bands located at 1440-1300 and $1070-1030 \mathrm{~cm}^{-1}$ indicated the trace presence of nitrate ions in the low-temperature $\left(100^{\circ} \mathrm{C}\right)$ samples. Because of the appearance of bands that are due to $\mathrm{CO}_{2}$ adsorbed on the metal cations, the decrease in the intensity of the bands due to citrate/carboxylate groups and the lower intensity of the $\mathrm{H}_{2} \mathrm{O}$ stretching band, one may conclude that the metal-carbonyl links begin to break after heating to $>350^{\circ} \mathrm{C}$. Samples that were calcined at $700^{\circ} \mathrm{C}$ basically show the $\mathrm{CO}_{3}^{2-}$ and $\mathrm{OH}^{-}$ions in their IR spectra. After calcination at $1200^{\circ} \mathrm{C}$, all IR bands that were attributed to anion vibrations disappeared in all the samples. However, the extraordinary affinity of LSG samples (see Fig. 6) for atmospheric $\mathrm{CO}_{2}$ should hereby be noted, which was a situation that was not observed for LG and LSGM samples.

The powder morphology of the LSGM powders, as a function of calcination temperature, was exhibited in the SEM micrographs that are shown in Fig. 8. The initially X-ray-amorphous resin particles (Fig. 8(a), of irregular morphology) began to crumble at temperatures of $>500^{\circ} \mathrm{C}$; after calcination at $1000^{\circ} \mathrm{C}$, the bigger chunks consisted of smaller particles $(\sim 0.2 \mu \mathrm{m})$ that were fused together (see Figs. 8(b)-(e)). The BET surface area of the LSGM samples was measured, as a function of calcination temperature, and the results were as follows: the $100^{\circ} \mathrm{C}$-heated sample had a surface area of $15.3 \mathrm{~m}^{2} / \mathrm{g}$, the $500^{\circ} \mathrm{C}$-heated sample had a surface area of $10.6 \mathrm{~m}^{2} / \mathrm{g}$, the $700^{\circ} \mathrm{C}$-heated sample had a surface area of $6.2 \mathrm{~m}^{2} / \mathrm{g}$, and the $1000^{\circ} \mathrm{C}$-heated sample had a surface area of 4.1 $\mathrm{m}^{2} / \mathrm{g}$.

The fracture surface of a pellet of LSGM powder (cold isostatically pressed at $650 \mathrm{MPa}$ and then calcined at $1400^{\circ} \mathrm{C}$ for $8 \mathrm{~h}$ in air) indicated that, after sintering, the final grain size was still $\leq 2 \mu \mathrm{m}$ (see Figs. 8(f) and (g)). In comparison to the mixed-oxide route of ceramic synthesis, which produces larger grains after solid-state reactive sintering, the Pechini process hereby provides a clear advantage in terms of the final, sintered grain size. However, the measured density of the sintered pellets (as determined using the Archimedes method) was $\sim 85 \%$ of the theoretical density, because of the presence of hard agglomerates in the green powders. The green density of such pellets varied in the range of $40 \%-45 \%$. The problem of densification in chemically prepared LSGM samples has been reported previously by Huang et al. ${ }^{18}$ and the sintered density of our powders agreed well with the values that were reported in their study. The presence of a $\mathrm{LaSrGa}_{3} \mathrm{O}_{7} / \mathrm{LaSrGaO}_{4}$ secondary phase was clearly visible (as darker grains) in the SEM micrograph that is shown in Fig. $8(\mathrm{~g})$. This micrograph was taken from a region of that sample which contained the secondary-phase grains, although areas that were free of those grains could be found in the same sample.

\section{Conclusions}

A Pechini-type polymeric precursor route has been used to synthesize powders with a $\mathrm{LaGaO}_{3}$ (LG), $\mathrm{La}_{0.9} \mathrm{Sr}_{0.1} \mathrm{GaO}_{2.95}$ (LSG), and $\mathrm{La}_{0.8} \mathrm{Sr}_{0.2} \mathrm{Ga}_{0.83} \mathrm{Mg}_{0.17} \mathrm{O}_{2.815}$ (LSGM) stoichiometry. Although single-phase LG and LSG powders were synthesized successfully after calcination at temperatures of $850^{\circ}$ and $1340^{\circ} \mathrm{C}$, respectively, the LSGM powders still contained $\sim 4-5 \mathrm{wt} \%$ of a $\mathrm{LaSrGa}_{3} \mathrm{O}_{7} / \mathrm{LaSrGaO}_{4}$ secondary phase after calcination at $1400^{\circ} \mathrm{C}$ for $8 \mathrm{~h}$. According to the results of Fourier transform infrared spectroscopy analyses, LSG samples, at all temperatures, have shown an increased affinity for atmospheric $\mathrm{CO}_{2}$, in comparison with LG powders. Calcination of LG, LSG, and LSGM precursors at temperatures of $>1000^{\circ} \mathrm{C}$ was necessary to reduce the carbon content to ppm levels.

\section{Acknowledgments}

The authors would like to thank Miss Heike Schluckwerder for her assistance with the sample preparations for the carbon and nitrogen analyses. Author ACT gratefully acknowledges the Max-Planck-Institut für Metallforschung of Stuttgart for the award of Visiting Professorship (extending over the term from Feb. 1999 to Feb. 2001). The authors also express their gratitude to G. Kaiser (ICP-AES), M. Thomas (XRD), H. Labitzke (SEM), W. Konig (FTIR), F. Predel (SEM/EDS), S. Hammoud (carbon and nitrogen analyses), and U. Heinrichs (BET) for their generous help in sample characterization.

\section{References}

${ }^{1}$ T. Ishihara, H. Matsuda, and Y. Takita, "Doped $\mathrm{LaGaO}_{3}$ Perovskite Type Oxide as a New Oxide Ionic Conductor," J. Am. Chem. Soc., 116, 3801-803 (1994).

${ }^{2}$ M. Feng and J. B. Goodenough, "A Superior Oxide-Ion Electrolyte," Eur. J. Solid State Inorg. Chem., T31, 663-72 (1994).

${ }^{3}$ P. Huang and A. Petric, "Superior Oxygen Ion Conductivity of Lanthanum Gallate Doped with Strontium and Magnesium," J. Electrochem. Soc., 143, 1644-48 (1996).

${ }^{4}$ K. Huang, R. S. Tichy, and J. B. Goodenough, "Superior Perovskite Oxide-Ion Conductor; Strontium- and Magnesium-Doped $\mathrm{LaGaO}_{3}$ : I, Phase Relationships and Electrical Properties," J. Am. Ceram. Soc., 81 [10] 2565-75 (1998).

${ }^{5}$ K. Huang, M. Feng, C. Milliken, and J. B. Goodenough, "Electrode Performance Test on Single Ceramic Fuel Cells Using as Electrolyte Sr- and Mg-doped $\mathrm{LaGaO}_{3}$," J. Electrochem. Soc., 144, 3620-24 (1997)

${ }^{6}$ J. Drennan, V. Zelizko, D. Hay, F. T. Ciacchi, S. Rajendran, and S. P. S. Badwall, "Characterisation, Conductivity and Mechanical Properties of the Oxygen-Ion Conductor $\mathrm{La}_{0.9} \mathrm{Sr}_{0.1} \mathrm{Ga}_{0.8} \mathrm{Mg}_{0.2} \mathrm{O}_{3-x}$," J. Mater. Chem., 7, 79-83 (1997).

${ }^{7}$ N. M. Sammes, F. M. Keppeler, H. Näfe, and F. Aldinger, "Mechanical Properties of Solid-State-Synthesized Strontium- and Magnesium-Doped Lanthanum Gallate," J. Am. Ceram. Soc., 81 [12] 3104-108 (1998).

${ }^{8}$ S. Baskaran, C. A. Lewinsohn, Y-S. Chou, M. Qian, J. W. Stevenson, and T. R. Armstrong, "Mechanical Properties of Alkaline Earth-Doped Lanthanum Gallate," $J$. Mater. Sci., 34, 3913-22 (1999).

${ }^{9}$ J. W. Stevenson, T. R. Armstrong, D. E. McCready, L. R. Pederson, and W. J. Weber, "Processing and Electrical Properties of Alkaline Earth-Doped Lanthanum Gallate," J. Electrochem. Soc., 144, 3613-20 (1997).

${ }^{10}$ J. J. Kingsley and K. C. Patil, "A Novel Combustion Process for the Synthesis of Fine Particle $\alpha$-Alumina and Related Oxide Materials," Mater. Lett., 6, 427-32 (1988).

${ }^{11}$ L. A. Chick, L. R. Pederson, G. D. Maupin, J. L. Bates, L. E. Thomas, and G. J. Exarhos, "Glycine-Nitrate Combustion Synthesis of Oxide Ceramic Powders," Mater. Lett., 10, 6-12 (1990).

${ }^{12}$ E. Taspinar and A. C. Taş, "Low-Temperature Chemical Synthesis of Lanthanum Monoaluminate," J. Am. Ceram. Soc., 80 [1] 133-41 (1997).

${ }^{13}$ A. C. Taş, "Chemical Preparation of the Binary Compounds in the CalciaAlumina System by Self-Propagating Combustion Synthesis," J. Am. Ceram. Soc., 81 [11] 2853-63 (1998).

${ }^{14}$ I. E. Gonenli and A. C. Taş, "Chemical Synthesis of Pure and Gd-doped $\mathrm{CaZrO}_{3}$ Powders," J. Eur. Ceram. Soc., 19, 2563-67 (1999).

${ }^{15}$ A. C. Taş, "Combustion Synthesis of Calcium Phosphate Bioceramic Powders," J. Eur. Ceram. Soc., 20 [14-15] 2389-94 (2000). 
${ }^{16}$ T. Mathews, J. R. Sellar, B. C. Muddle, and P. Manoravi, "Pulsed Laser Deposition of Doped Lanthanum Gallate and In Situ Analysis by Mass Spectrometry of the Laser Ablation Plume," Chem. Mater., 12, 917-22 (2000).

${ }^{17}$ K. Huang, M. Feng, and J. B. Goodenough, "Sol-Gel Synthesis of a New Oxide-Ion Conductor Sr-and Mg-Doped $\mathrm{LaGaO}_{3}$ Perovskite," J. Am. Ceram. Soc., 79 [4] 1100-104 (1996).

${ }^{18} \mathrm{~K}$. Huang and J. B. Goodenough, "Wet Chemical Synthesis of Sr- and Mg-Doped $\mathrm{LaGaO}_{3}$, a Perovskite-Type Oxide-Ion Conductor," J. Solid State Chem., 136, 274-83 (1998).

${ }^{19}$ M. Pechini, "Method of Preparing Lead and Alkaline Earth Titanates and Niobates and Coating Method Using the Same to Form a Capacitor," U.S. Pat. No. 3330697 , July 11, 1967.

${ }^{20}$ N. G. Eror and H. U. Anderson, "Polymeric Precursor Synthesis of Ceramic Materials," Mater. Res. Soc. Symp. Proc., 73, 571-77 (1986).

${ }^{21}$ P. A. Lessing, "Mixed-Cation Oxide Powders via Polymeric Precursors," Am. Ceram. Soc. Bull., 68 [5] 1002-1007 (1989).

${ }^{22}$ (a)L.-W. Tai and P. A. Lessing, "Modified Resin-Intermediate Processing of Perovskite Powders: Part I. Optimization of Polymeric Precursors," J. Mater. Res., 7, 502-19 (1992). (b)L.-W. Tai and P. A. Lessing, "Modified Resin-Intermediate Processing of Perovskite Powders: Part II. Processing for Fine, Nonagglomerated Sr-Doped Lanthanum Chromite Powders," J. Mater. Res., 7, 502-19 (1992).
${ }^{23}$ H. U. Anderson, "Review of $p$-type Perovskite Materials for SOFC and Other Applications," Solid State Ionics, 52, 33-41 (1992).

${ }^{24}$ L.-W. Tai, H. U. Anderson, and P. A. Lessing, "Mixed-Cation Oxide Powders via Resin Intermediates Derived from a Water-Soluble Polymer," J. Am. Ceram. Soc., 75 [12] 3490-94 (1992).

${ }^{25} \mathrm{C}$. Basceri, A. C. Taş, and M. Timucin, "Characterization of New Solid Solution Phases in $(\mathrm{Y}, \mathrm{Ca})(\mathrm{Cr}, \mathrm{Co}) \mathrm{O}_{3}$ System," Powder Diffr., 10, 40-43 (1995).

${ }^{26}$ D. E. Appleman and H. T. Evans, "Indexing and Least-Squares Refinement of Powder Diffraction Data," U.S. Geol. Surv., GD-73-003 (1973).

27"Standard Test Method for Water Absorption, Bulk Density, Apparent Porosity, and Apparent Specific Gravity of Fired Whiteware Products," ASTM Designation C372-73, 1973 Annual Book of Standards. American Society for Testing and Materials, West Conshohocken, PA.

${ }^{28}$ P. R. Slater, J. T. S. Irvine, T. Ishihara, and Y. Takita, "The Structure of the Oxide Ion Conductor $\mathrm{La}_{0.9} \mathrm{Sr}_{0.1} \mathrm{Ga}_{0.8} \mathrm{Mg}_{0.2} \mathrm{O}_{2.85}$ by Powder Neutron Diffraction," Solid State Ionics, 107, 319-23 (1998).

${ }^{29}$ M. Rozumek, "Phase Equilibria Studies in the Quaternary Solid Oxide Fuel Cell System $\mathrm{La}_{2} \mathrm{O}_{3}-\mathrm{SrO}-\mathrm{MgO}-\mathrm{Ga}_{2} \mathrm{O}_{3}$ via Solution Chemical Processing Routes"; Ph.D. Thesis (Thesis Supervisor: Dr. P. J. Majewski). Max-Planck-Institute für Metallforschung, Stuttgart, Germany, in progress. 